\title{
Odin-OSIRIS stratospheric aerosol data product and SAGE III intercomparison
}

\author{
A. E. Bourassa, L. A. Rieger, N. D. Lloyd, and D. A. Degenstein \\ Institute of Space and Atmospheric Studies, University of Saskatchewan, Canada \\ Correspondence to: A. Bourassa (adam.bourassa@usask.ca) \\ Received: 5 July 2011 - Published in Atmos. Chem. Phys. Discuss.: 16 September 2011 \\ Revised: 4 January 2012 - Accepted: 5 January 2012 - Published: 12 January 2012
}

\begin{abstract}
The scattered sunlight measurements made by the Optical Spectrograph and InfraRed Imaging System (OSIRIS) on the Odin spacecraft are used to retrieve vertical profiles of stratospheric aerosol extinction at $750 \mathrm{~nm}$. The recently released OSIRIS Version 5 data product contains the first publicly released stratospheric aerosol extinction retrievals, and these are now available for the entire Odin mission, which extends from the present day back to launch in 2001. A proof-of-concept study for the retrieval of stratospheric aerosol extinction from limb scatter measurements was previously published and the Version 5 data product retrievals are based on this work, but incorporate several important improvements to the algorithm. One of the primary changes is the use of a new retrieval vector that greatly improves the sensitivity to aerosol scattering by incorporating a forward modeled calculation of the radiance from a Rayleigh atmosphere. Additional improvements include a coupled retrieval of the effective albedo, a new method for normalization of the retrieval vector to improve signal-to-noise, and the use of an initial guess that is representative of very low background aerosol loading conditions, which allows for maximal retrieval range. Furthermore, the Version 5 data set is compared to Stratospheric Aerosol and Gas Experiment (SAGE) III $755 \mathrm{~nm}$ extinction profiles during the almost four years of mission overlap from 2002 to late 2005. The vertical structure in coincident profile measurements is well correlated and the statistics on a relatively large set of tight coincident measurements show agreement between the measurements from the two instruments to within approximately $10 \%$ throughout the 15 to $25 \mathrm{~km}$ altitude range, which covers the bulk of the stratospheric aerosol layer for the mid and high latitude cases studied here.
\end{abstract}

\section{Introduction}

Stratospheric aerosol has been measured from space for decades by solar occultation, and the long-standing heritage and accuracy of these aerosol extinction measurements, in particular from the Stratospheric Aerosol and Gas Experiment (SAGE) series of instruments (SAGE, 1979 to 1981; SAGE II, 1984 to 2005; SAGE III, 2002 to 2005), has provided an essential understanding of the stratospheric aerosol layer, particularly the impact of volcanic eruptions. The occultation technique is inherently stable through the built-in calibration measurement of the exo-atmospheric sun for each profile. It is also a direct measurement of the atmospheric optical depth, which is relatively easy to convert to aerosol extinction without requiring any assumptions regarding the aerosol composition or size.

In the past decade, a number of satellite instruments capable of making spectral observations of limb scattered sunlight have been in operation including the Optical Spectrograph and InfraRed Imaging System (OSIRIS), SAGE III (Rault, 2005; Rault and Loughman, 2007) and the SCanning Imaging Absorption spectroMeter for Atmospheric CartograpHY (SCIAMACHY) (Bovensmann et al., 1999) and Global Ozone Monitoring by Occultation of Stars (GOMOS) (Bertaux et al., 2010). Several studies have shown the capability for the retrieval of vertical profiles of stratospheric aerosol parameters from measurements of the limb radiance at visible and near infrared wavelengths (Bourassa et al., 2007, 2008b; Rault and Loughman, 2007; Tukiainen et al., 2008). The limb scatter measurement technique has a distinct benefit over occultation in terms of sampling; vertical profiles can be obtained repetitively for tangent points in the sunlit hemisphere providing nearly global coverage within a relatively short time period. However, the effect of stratospheric aerosol is a small component of the limb signal with 
a broad, smooth spectral signature making the retrieval of aerosol information difficult. In addition, the retrieval requires a detailed forward model calculation with accurate account of multiple scattering terms and assumptions regarding the microphysical and optical properties of the aerosol in order to characterize the scattering properties.

The OSIRIS instrument, which is onboard the Swedish satellite Odin, is designed to measure the vertical profile of atmospheric limb radiance spectra at wavelengths from the near ultra-violet to the near infra-red $(274 \mathrm{~nm}$ to $810 \mathrm{~nm})$. The satellite was launched on 20 February 2001, into a sunsynchronous polar orbit and continues full operation to the present date providing a valuable data record that now spans a decade of observation. For further details on OSIRIS and Odin, see Llewellyn et al. (2004), and Murtagh et al. (2002), respectively.

Vertical profile information is obtained by successive vertical scans of the instrument's line-of-sight, which has a fieldof-view that is $1 \mathrm{~km}$ in the vertical and $40 \mathrm{~km}$ in the horizontal the tangent point. The scanning speed combined with the exposure rate dictates the sampling resolution of the measurements, which is approximately $2 \mathrm{~km}$ vertically, with successive scans approximately every 5 degrees along the satellite track, which is about $550 \mathrm{~km}$. The local time of the ascending node of the Odin orbit is $18: 00 \mathrm{~h}$. This configuration provides measurements of the sunlit summer hemisphere, global measurements during equinox, and no coverage of the mid to high latitude winter hemisphere. Northern high latitude measurements cease by mid-November when the line of sight is no longer illuminated. The $98^{\circ}$ inclination of the orbit provides sampling of all latitudes up to $82^{\circ}$ during normal aeronomy operations.

A stratospheric aerosol retrieval was developed for use with the OSIRIS measurements by Bourassa et al. (2007). This algorithm used a spectral ratio as the retrieval vector and the SASKTRAN forward model for radiative transfer calculations (Bourassa et al., 2008a). The inversion was performed using the Multiplicative Algebraic Relaxation Technique, which has now also been used successfully in the retrieval of ozone (Degenstein et al., 2009) and nitrogen dioxide (Bourassa et al., 2011) from the OSIRIS measurements. Herein we provide the details of several important improvements to this retrieval algorithm; these are used in the production of the first OSIRIS stratospheric aerosol data product for public release, Version 5. In Sect. 2 we present an alternative retrieval vector that increases the sensitivity to aerosol, resulting in faster convergence and a more sharply peaked averaging kernel in the lower stratosphere. Additionally, we discuss an improved technique for normalization of the retrieval vector, a coupled retrieval of the retrieval, and the importance of the initial estimate. In Sect. 3, the OSIRIS results are compared with coincident and zonally average SAGE III measurements. In Sect. 4, the features of the OSIRIS Version 5 data set are highlighted and conclusions are provided in Sect. 5.

\section{Retrieval algorithm}

\subsection{Original retrieval algorithm}

In the original work by Bourassa et al. (2007) the retrieval vector for stratospheric aerosol was defined as,

$y_{j}=\ln \left(\frac{\tilde{I}\left(j, \lambda_{2}\right)}{\tilde{I}\left(j, \lambda_{1}\right)}\right)$,

where $\tilde{I}(j, \lambda)$ represents the radiance at tangent altitude $j$ and wavelength $\lambda$, normalized by the radiance at the same wavelength from a higher reference tangent altitude, $j_{r}$,

$\tilde{I}(j, \lambda)=\frac{I(j, \lambda)}{I\left(j_{r}, \lambda\right)}$.

As discussed in Bourassa et al. (2007), this retrieval vector, where $\lambda_{2}>\lambda_{1}$, is dependent in a positive sense on the Mie scattering contribution to the line of sight radiance in that as the Mie scattering contribution is increased, the retrieval vector increases. This is due to the fact that the wavelength dependence of the aerosol scattering is typically much weaker than that of the Rayleigh background. For the OSIRIS measurements, we have chosen $\lambda_{2}=750 \mathrm{~nm}$ and $\lambda_{1}=470 \mathrm{~nm}$ in order to maximize the spread between the wavelengths without losing sensitivity to lower stratospheric tangent heights. This is also discussed in detail in Bourassa et al. (2007).

The normalization tangent altitude was chosen, on a scan by scan basis, as the highest tangent altitude above which stray light becomes systematically larger than the measurement noise. The stray light signal is easily identified as a systematic anomalous increase in signal at high tangent altitude. For the OSIRIS measurements this is typically above the majority of the stratospheric aerosol layer. In practice, the normalization tangent altitude is typically between 30 and $35 \mathrm{~km}$. Figure 1 shows an example of the retrieval vector calculated in this fashion in the left panel. This particular measurement was made by OSIRIS during April 2002 at midlatitude and is typical of a measurement made during background stratospheric aerosol conditions. The normalization tangent altitude for this scan is $35 \mathrm{~km}$, which is the point where the retrieval vector goes to zero by definition. A large component of the characteristic shape of this retrieval vector is smooth and monotonically increasing with decreasing tangent altitude due to the difference in optical depth of the Rayleigh atmosphere between the two wavelengths in the retrieval vector. Deviations from this exponential-like characteristic shape are due to aerosol. These deviations are typically positive, and are due to the relatively weaker wavelength dependence of the aerosol scattering cross section. For example, in this profile the peak of the Junge layer is evident at $22 \mathrm{~km}$ tangent altitude along with a enhancement due to cloud at $11 \mathrm{~km}$ tangent altitude.

By using Mie theory to calculate scattering phase functions and the scattering cross section ratio for an assumed 

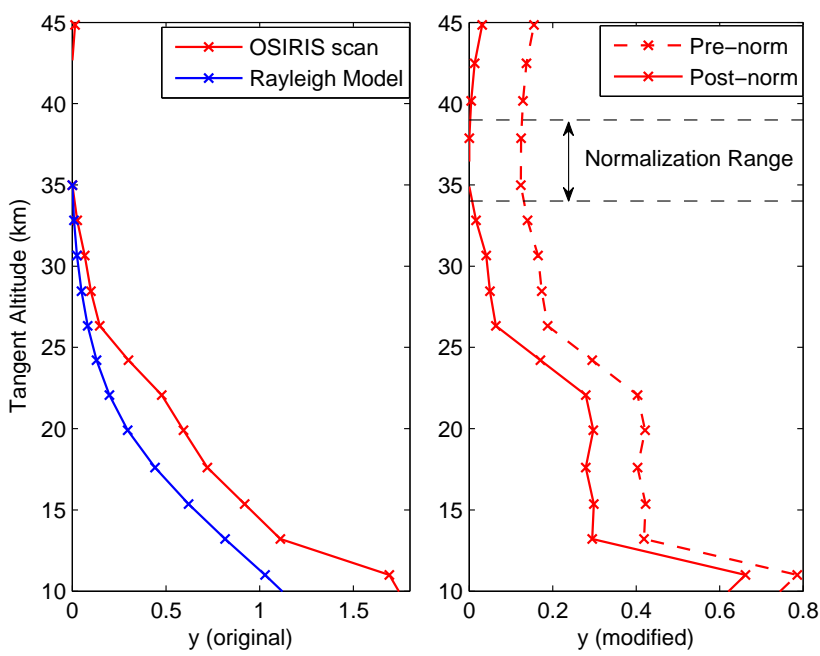

Fig. 1. The stratospheric aerosol retrieval vector, $\boldsymbol{y}$. The left panel shows $\boldsymbol{y}$ as calculated according the original algorithm for a typical OSIRIS scan in red as well as $\boldsymbol{y}$ for a model calculation of an aerosol-free atmosphere in blue. The right panel shows the modified version of $\boldsymbol{y}$, before and after the normalization (with dashed red and solid red lines according to Eqs. (4) and (5) respectively).

particle size distribution, the retrieval algorithm fits the forward model retrieval vector to the measurement by iteratively updating the aerosol extinction. In all of the following work, the particle size distribution is assumed to be single mode log-normal with a mode radius of $80 \mathrm{~nm}$ and a mode width of 1.6. These are representative of typical background conditions (Deshler et al., 2003). The solution is then found using a Multiplicative Algebraic Reconstruction Technique (MART), namely,

$x_{i}^{(n+1)}=x_{i}^{(n)} \sum_{j}\left(\frac{y_{j}^{\mathrm{obs}}}{y_{j}^{\bmod }} W_{j i}\right)$,

where the iterative adjustment of the state parameter $x$ at an altitude $i$ is found by scaling the value of the state parameter from the previous iteration by a value that is based on the ratio of the measured, or observed, and modelled retrieval vectors. In this case, the state parameter is the aerosol extinction profile. Further detail on the MART method and the determination of the weighting factors $W_{j i}$ are provided in Bourassa et al. (2007), Degenstein et al. (2004), Degenstein et al. (2009) and Bourassa et al. (2011).

Simulations performed by Bourassa et al. (2007) demonstrated the feasibility of the technique; however, convergence is slow and the width of the averaging kernel increases below $20 \mathrm{~km}$ resulting in a smoothing of vertical features. This can be understood to some degree by examining the sensitivity of the retrieval vector. As shown in Eq. (3), if the measured retrieval vector is greater than the modelled result, this is an indication that more aerosol is required in the modelled atmospheric state. However, the multiplicative factor used to update the state parameter in Eq. (3), which is term encompassed by the summation, is non-linear due to the large contribution in the retrieval vector from the Rayleigh background. That is, if the retrieval vector calculated by the model is half of that of the observation, considerably more than double the current value of aerosol extinction in the forward model is required for convergence. In the following section we present an alternative retrieval vector that increases the sensitivity to aerosol, resulting in faster convergence and a more sharply peaked averaging kernel in the lower stratosphere.

\subsection{Modified retrieval vector}

In addition to the retrieval vector as defined by Bourassa et al. (2007), the left panel of Fig. 1 also shows the same retrieval vector calculated using forward model radiances obtained using the SASKTRAN model. The SASKTRAN model is a spherical geometry code that solves the radiative transfer equation with multiple scattering using the successive orders of scattering technique. For details see Bourassa et al. (2008a). This SASKTRAN calculation was performed using European Centre for Medium-Range Weather Forecasts (ECMWF) pressure and temperature profiles interpolated to the OSIRIS scan location; the ozone and nitrogen dioxide profiles were taken from OSIRIS retrievals of these parameters for this scan. The model calculation has no aerosol, i.e. it is the result for a molecular, or Rayleigh, atmosphere. As such, the characteristic shape of the retrieval vector follows the smooth exponential-like profile discussed above and is considerably lower in value than the retrieval vector due to the lack of contribution from aerosol scattering.

A modified formulation of the retrieval vector is obtained by taking the difference between the logarithm of the spectral ratio for the measurements and the same for the modelled Rayleigh atmosphere,

$y_{j}=\ln \left(\frac{I\left(j, \lambda_{2}\right)}{I\left(j, \lambda_{1}\right)}\right)-\ln \left(\frac{I_{\text {Ray }}\left(j, \lambda_{2}\right)}{I_{\text {Ray }}\left(j, \lambda_{1}\right)}\right)$.

In an optically thin atmosphere, this retrieval vector formulation is, to first order, a measure of the aerosol scattering signal only, without a contribution from Rayleigh scattering. This is not strictly true due to the contribution from multiple scattering; however, now the multiplicative update factor for the retrieval iterations is much closer to a one-to-one relationship with the aerosol content, i.e. now a modelled retrieval vector that has half the value of the measurement at a given tangent altitude corresponds to a required increase in the aerosol extinction by approximately a factor of two.

The averaging kernel matrix corresponding to each of these two different retrieval vectors is shown in Fig. 2. These are calculated numerically by perturbation of a typical aerosol extinction profile at each altitude and successive retrieval using simulated radiances for each state. The radiances are simulated with $1 \mathrm{~km}$ tangent altitude spacing and 

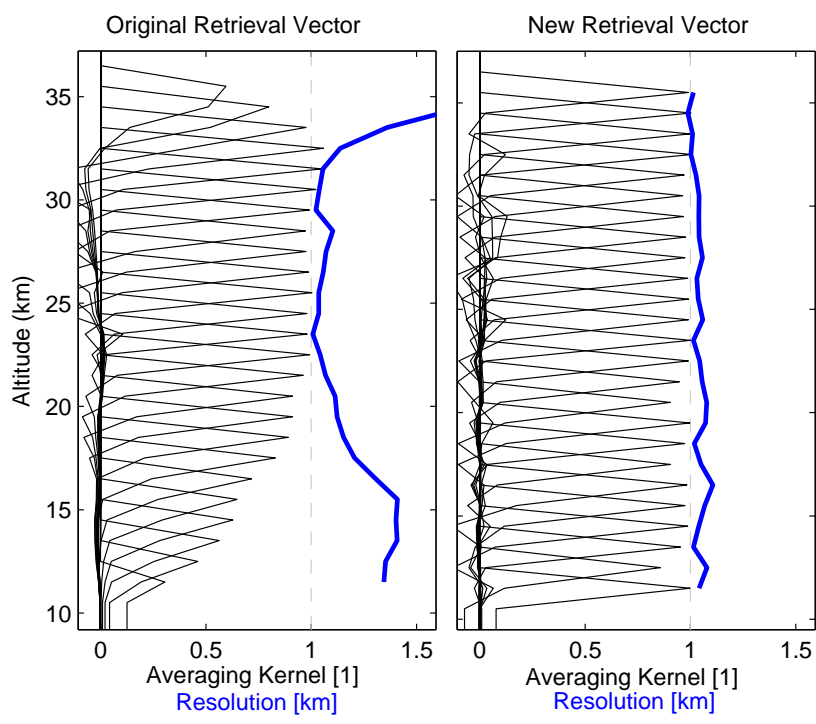

Fig. 2. The averaging kernel in black and resolution in terms of Full Width Half Maximum (FWHM) in blue for a simulated aerosol retrieval using lines-of-sight spaced $1 \mathrm{~km}$ in tangent altitude. The left panel shows the result when using the retrieval vector defined in Eq. (1). The right panel shows the improvement when using the retrieval vector defined in Eq. (5).

the resolution is calculated as the full-width half-maximum of each curve. The peaks of the averaging kernel that correspond to the modified retrieval vector, which is shown in the right panel, are close to unity down to $10 \mathrm{~km}$ and the resolution is essentially equal to the line-of-sight sampling at all altitudes. This is a significant improvement over the previous method, which is shown in the left panel, where the resolution is degraded below $20 \mathrm{~km}$ and above $32 \mathrm{~km}$ altitude.

\subsection{Retrieval vector normalization}

The motivation for the upper tangent altitude normalization of limb scattered radiances is typically twofold: it decreases the sensitivity of the retrieval vector to the effective albedo, and it removes the requirement for an absolute calibration of the measurements. The modelled and measured states can then be compared directly in the inversion. However, the signal to noise ratio is falling at high tangent altitude and the standard normalization technique, which uses a single measurement from this range, is susceptible to noise. It is advantageous to consider, then, using multiple measurements from a range of high altitudes for the normalization, and yet because the radiance is falling off exponentially with tangent altitude, simply averaging several radiances does not give equal weight to each measurement. Instead we use several points of the retrieval vector itself to calculate an offset, which then functions in the same way as the normalization but allows for the incorporation of multiple measurements in an unbiased way.
Due to the logarithm, a simple normalization of the radiances is equivalent to a systematic offset of the retrieval vector, i.e. the logarithm of a ratio can be written as the difference of the logarithm of each term. This offset is constant with tangent altitude and results in a value of identically $\ln (1)=0$ at the normalization tangent altitude. Following this logic, a normalized retrieval vector is written as,

$y_{j}=\ln \left(\frac{I\left(j, \lambda_{2}\right)}{I\left(j, \lambda_{1}\right)}\right)-\ln \left(\frac{I_{\text {Ray }}\left(j, \lambda_{2}\right)}{I_{\text {Ray }}\left(j, \lambda_{1}\right)}\right)-\delta$,

where the offset term, $\delta$, is the value of $y_{j}$ at the normalization tangent altitude,

$\delta=\ln \left(\frac{I\left(j_{r}, \lambda_{2}\right)}{I\left(j_{r}, \lambda_{1}\right)}\right)-\ln \left(\frac{I_{\text {Ray }}\left(j_{r}, \lambda_{2}\right)}{I_{\text {Ray }}\left(j_{r}, \lambda_{1}\right)}\right)$.

This is an equivalent expression of the normalization of the retrieval vector shown in Eqs. (1) and (2). We now take this one step further and use several measurements in the calculation of $\delta$ in order to improve the signal-to-noise,

$\delta=\frac{1}{N} \sum_{j=m}^{m+N}\left(\ln \left(\frac{I\left(j, \lambda_{2}\right)}{I\left(j, \lambda_{1}\right)}\right)-\ln \left(\frac{I_{\text {Ray }}\left(j, \lambda_{2}\right)}{I_{\text {Ray }}\left(j, \lambda_{1}\right)}\right)\right)$.

Thus $\delta$ is the average value of Eq. (4) taken over the range of $N$ lines-of-sight beginning with tangent altitude $j=m$. In this case, the average value of the retrieval vector given in Eq. (5) over this same range is zero. The retrieval vector calculated using this method is shown in the right panel of Fig. 1 where the two lines-of-sight between 34 and $38 \mathrm{~km}$ are used to compute the offset. The curves shown correspond to calculations performed using Eqs. (4) and (5).

The Version 5 retrieval algorithm determines the range over which to determine the offset, $\delta$, based on the measurements on a scan by scan basis. The minimum value of the vector calculated according to Eq. (4) is first determined and all values within a contiguous range that fall within a threshold of the minimum value are used in the average. The threshold is determined using a signal to noise criteria based on the measurements, such that any signal greater than the expected instrument noise level is considered either stray light or aerosol scattering and not used in the averaging. In practice, the range of tangent altitudes used to determine the offset is typically between 35 and $40 \mathrm{~km}$ in the tropics. At mid to high latitude, the normalization range usually extends lower to approximately $27-30 \mathrm{~km}$ and can include measurements up to $40 \mathrm{~km}$. The lower level of the offset range is higher in the tropics because the aerosol load of the tropical stratosphere typically extends to around $35 \mathrm{~km}$. Thus the range of tangent altitudes that can be used to determine the offset at mid and high latitude is larger due to the fact that the instrumental stray light, which is the limiting factor for the upper level of the range, generally does not become significant until approximately $40 \mathrm{~km}$. 


\subsection{Coupled albedo retrieval}

The albedo of the surface is one of the most important forward model parameters in terms of uncertainty in the retrieved aerosol extinction (Bourassa et al., 2007). In the original algorithm, the effective Lambertian surface albedo is first retrieved at $750 \mathrm{~nm}$ by matching the measured and modelled radiance, in an absolute sense, for the line-of-sight nearest to $40 \mathrm{~km}$ tangent altitude. This point was chosen for essentially the same reasons as the normalization point for the retrieval vector: it is above the majority of the signal from the aerosol layer and below the altitude where stray light becomes significant. Through a forward model study, Bourassa et al. (2007) determined that the uncertainty in the aerosol retrieval due to albedo is then limited to approximately $10 \%$ for OSIRIS measurements. However, we have discovered an important coupling between the stratospheric aerosol load and the albedo retrieved using the $40 \mathrm{~km}$ radiance. Even though the albedo retrieval is performed at tangent altitudes above the stratospheric aerosol layer, it is sensitive to the aerosol load. This can be explained through the strong forward scattering characteristic of the aerosol that will tend to amplify the upwelling signal at oblique angles to the line-of-sight that are near the forward direction. Thus we have found that it is important to first retrieve the albedo using an initial guess for the aerosol extinction profile, then retrieve the aerosol extinction profile, and then successively re-retrieve the albedo and the aerosol profile. The second retrieval of the albedo can differ from the first estimate by up to approximately $20 \%$ and this will typically reflect a change of approximately $10 \%$ in the retrieved aerosol extinction profile. Two iterations of this process are often sufficient, and the change in the albedo upon a third retrieval is typically less than $1 \%$.

\subsection{The initial estimate}

The aerosol Jacobian, or so-called weighting functions, are positive for limb scattering at mid-visible and near infrared wavelengths throughout most stratospheric lines-of-sight. That is, an increase in aerosol extinction, which translates into more scattering along the line of sight, results in an increase in the retrieval vector. However, at a certain tangent altitude, typically for lines of sight in the upper troposphere or lower stratosphere, the Jacobian becomes negative such that an increase in aerosol extinction results in a decrease in the retrieval vector. In this case, the effect of extinction is greater than the effect of increased aerosol scattering along the line of sight. The point where the Jacobian becomes negative is related to the total optical depth and as such, it increases in tangent altitude as the aerosol optical depth increases. This characteristic is problematic for the inversion algorithm due to the positivity constraint and the retrieval cannot take place below this point. The approach taken by Bourassa et al. (2007), and by others such as Rault and Loughman (2007), has been to use an a priori aerosol profile that represents the best knowledge of the true state and from that determine the retrieval range on the constraint of positive Jacobian values. This would be particularly problematic for the case of high volcanic aerosol load and the increased extinction would severely limit the lower altitude limit of a limb scatter retrieval. In principle, one could develop a wavelength dependent table that relates aerosol load to the lower altitude of the retrieval.

For the OSIRIS measurements, we have found that a robust strategy is to use extremely low values for the initial guess aerosol extinction profile. In this case, for the first iteration, the Jacobian is positive for all lines-of-sight down to the tropopause such that all stratospheric lines-of-sight are included in the retrieval range. After each iteration, the Jacobian can be calculated and the retrieval range for the next iteration determined from the positivity constraint. This ensures that the extinction profile is retrieved down to the lowest possible altitude. In practice, recalculation of the Jacobian on each iteration is not strictly necessary and for the Version 5 retrievals, we have used an extinction threshold that approximately represents the negative condition. The Jacobian is calculated after the final iteration in order to report the final retrieval range. With the new formulation of the retrieval vector detailed above, the inversion converges in only a few iterations, even with a very low value for the initial guess profile, which is a significant improvement over the original algorithm that required typically more that 20 iterations.

\section{SAGE III/OSIRIS intercomparison}

The validation of stratospheric aerosol measurements is difficult due to the large number of variables involved and the inherent differences in remote sensing techniques (see for example Thomason et al., 2010; Vanhellemont et al., 2010). The Assessment of Stratospheric Aerosol Properties document (SPARC, 2006) discusses the difficulty in converting lidar backscatter and optical particle counter measurements to reliable extinction values, particularly during the historically low levels of stratospheric aerosol loading which have been typical of the past decade. Although Thomason et al. (2010) state that there is no standard measurement with which to compare, the SAGE series of occultation measurements have been extensively evaluated and compared with other space based instruments and have been found to have relatively high precision and accuracy. These likely represent the best possible measurement with which to compare the OSIRIS results. We have chosen the SAGE III mission in particular as it has essentially four years of overlap with the OSIRIS mission and an aerosol extinction coefficient data product at $755 \mathrm{~nm}$, which is a very close match to the OSIRIS retrieval at $750 \mathrm{~nm}$. For the Northern Hemisphere the overlap period begins with the start of the SAGE III measurements in February 2002 and ends in 2005 when OSIRIS loses coverage of 
high latitudes in the Northern Hemisphere; the SAGE III mission terminated in March 2006, just as OSIRIS was beginning to regain coverage of the high latitudes. Version 4 of the SAGE III data products have been publicly available since 2008. The Version 4 evaluation study performed by Thomason et al. (2010) finds the $755 \mathrm{~nm}$ aerosol extinction data product to be a "solid channel" with accuracies and precisions on the order of $10 \%$ throughout the lower stratosphere. We have compared SAGE III $755 \mathrm{~nm}$ and OSIRIS $750 \mathrm{~nm}$ aerosol extinction coefficient retrievals directly without any attempt to compensate for the difference in wavelength. For stratospheric aerosol particle sizes, the angstrom coefficient generally ranges between 0 and 2 , such that in the worst case the systematic difference in wavelength would affect the comparison by less than $2 \%$.

\subsection{Coincidence statistics}

The coincidence criteria that we have chosen are quite tight; the reference tangent points of the OSIRIS and SAGE III measurements are within $\pm 6 \mathrm{~h}, \pm 1^{\circ}$ latitude, and $\pm 2.5^{\circ}$ longitude. These are considerably tighter than those typically used for occultation comparisons; for example Thomason et al. (2010) and Randall et al. (2001) use a criteria of \pm 1 day, $\pm 24^{\circ}$ longitude, and $\pm 5 \%$ of the potential vorticity (PV) range of the measurements spanning the Northern Hemisphere. The $5 \% \mathrm{PV}$ criteria is approximately equivalent to $\pm 2^{\circ}$ latitude; however it is used as it is often a better indication of the dynamical characteristics of the sampled volume. This is particularly true for measurements near the polar vortex edge in the winter. Because of the relatively large number of OSIRIS measurements at high latitude we have simply chosen a tight latitude criteria of $\pm 1^{\circ}$ to define a coincident measurement, and because OSIRIS is not able to make measurements during winter when the PV criteria would be most important we believe that this criteria is sufficient. Over the course of the entire overlap period this provides 479 coincident measurements of the aerosol extinction profile. None of the measurements that are included within this criteria are rejected in the following analysis.

Figure 3 shows a sample of four of these coincident measurements. These are a representative sample and the level of agreement shown in these four profiles is typical. In many cases the aerosol extinction coefficient profile is quite variable and shows multiple layers and small scale structure throughout the altitude range covering the bulk of the layer. The layered structure is detected by both instruments, even in multi-layer situations like that shown in the upper right panel. The OSIRIS extinction profiles are retrieved on a $1 \mathrm{~km}$ grid; however, as mentioned previously the vertical resolution is approximately $2 \mathrm{~km}$ due, which is lower than the $0.5 \mathrm{~km}$ resolution of the SAGE III measurements. This is evident in Fig. 3 where some of the finer structure that appears in the SAGE III measurement is not captured in the OSIRIS retrieval.

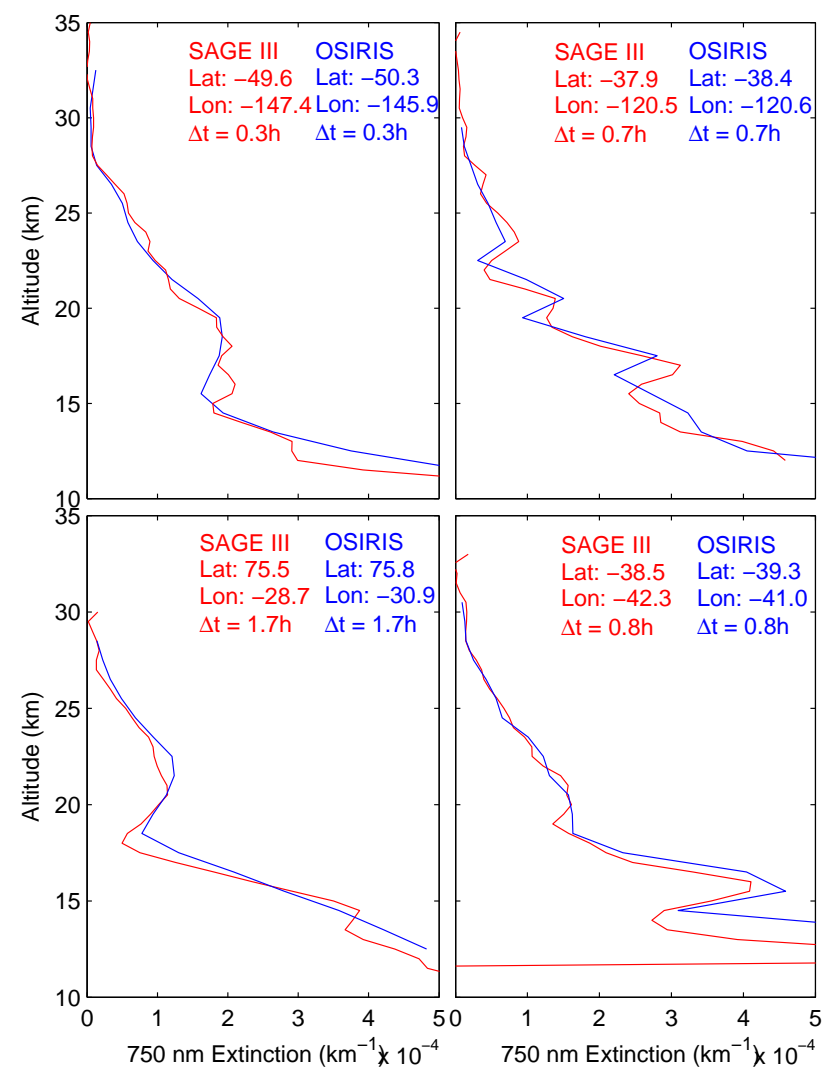

Fig. 3. Four coincident SAGE III and OSIRIS aerosol extinction coefficient measurements. SAGE III measurements at $755 \mathrm{~nm}$ are shown in red and OSIRIS measurements at $750 \mathrm{~nm}$ are shown in blue. The latitude, longitude of each measurement and the time difference between each coincident SAGE III and OSIRIS measurement are given in each corresponding plot.

Statistical results for the comparison of all of the SAGE III and OSIRIS coincidences are shown in Fig. 4 and Fig. 5. In Fig. 4, the coincidences are separated by year and the percent difference in extinction coefficient at each altitude reported for the OSIRIS retrieval is calculated according to the OSIRIS measurement minus the SAGE III measurement expressed as a percentage of the average of the two measurements. For all years, the general agreement is quite good with the average of the percent difference essentially less than $10 \%$ from 15 to $25 \mathrm{~km}$ with little to no consistent altitude trend from year to year. In 2005 there is a small positive bias of around $10 \%$ that is basically constant with altitude up to $25 \mathrm{~km}$ altitude. Above $25 \mathrm{~km}$, the differences increase somewhat, in part due to the very small values of absolute extinction at these altitudes. The standard deviation of the percent differences is also shown in Fig. 4; these are approximately $30 \%$ throughout the bulk of the layer and show the usual increase toward higher altitude where the aerosol extinction coefficient levels are falling and measurement error is increasing. This level of agreement is very similar to that 

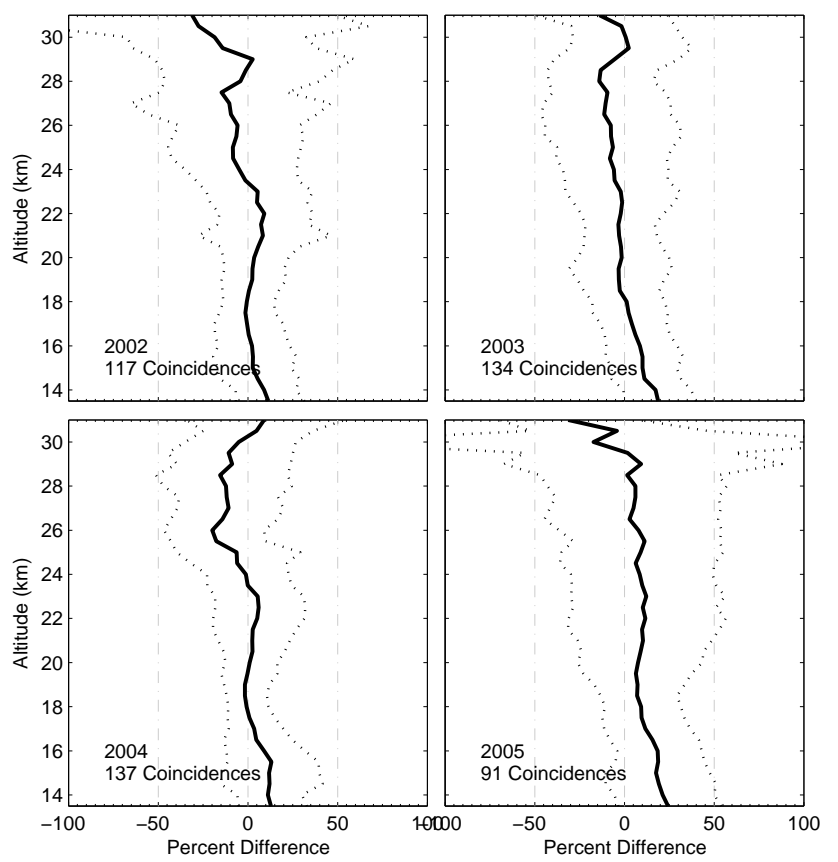

Fig. 4. The mean (solid) and standard deviation (dashed) of the percent difference of all OSIRIS and SAGE III coincidences over the four years of mission overlap, 2002-2005. Top left panel shows the results for 117 coincident measurements in 2002; top right panel shows the results for 134 coincident measurements in 2003; bottom left panel shows the results for 137 coincident measurements in 2004; and, bottom right panel shows the results for 91 coincident measurements in 2005 .

found by Thomason et al. (2010) in the comparison of SAGE III and Polar Ozone and Aerosol Measurements (POAM) III observations. For details on POAM III see Randall et al. (2001).

Complementary results from the comparison are presented in Fig. 5 and show a similar picture. Here the coincident SAGE III measurements are plotted as function of the OSIRIS measurement at four altitude levels throughout the lower stratosphere. These are again separated by year and the mean and standard deviation statistics reported on each panel are calculated following Thomason et al. (2010) according to the ratio,

$r=\frac{k_{\mathrm{OSIRIS}}(\lambda)}{k_{\mathrm{SAGEIII}}(\lambda)}$

where $k$ is the aerosol extinction coefficient. This is done in order to include all points in the profile within the same statistical set without biasing the result toward the larger values of extinction typically found at lower altitude. Again, this correlation analysis shows excellent agreement between the two instruments; for years 2002, 2003 and 2004, the mean value shows agreement to less than $10 \%$. The positive bias in 2005 is again evident, where the mean value of $r$ is approximately 1.2 , which means that the OSIRIS retrieved aerosol
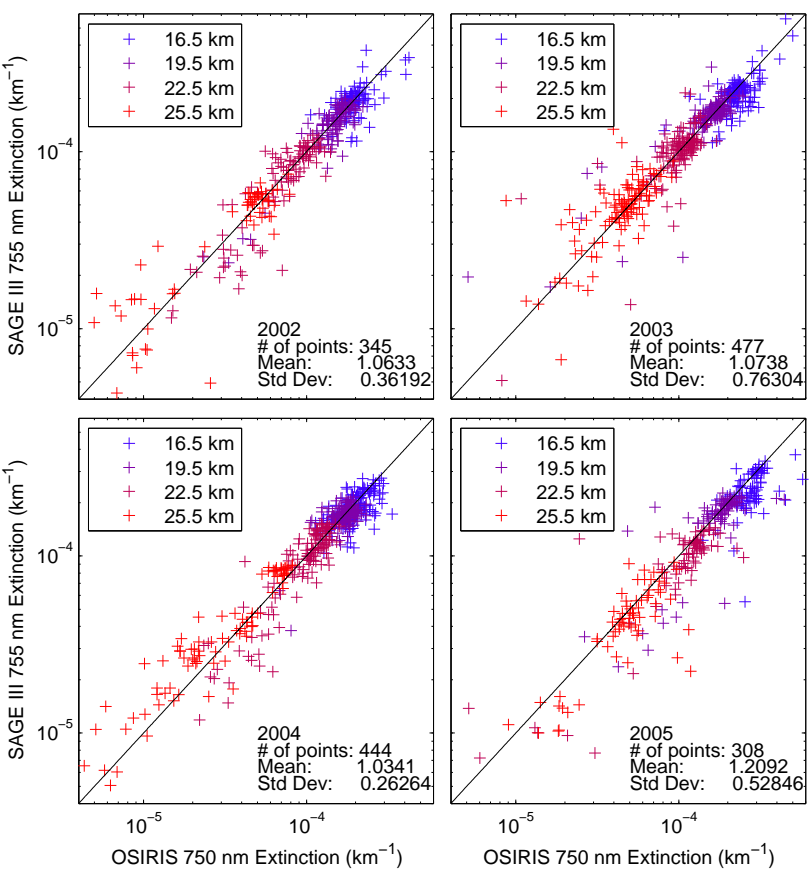

Fig. 5. Comparison of, for OSIRIS and SAGE III aerosol extinction coefficient at four altitude levels: $16.5 \mathrm{~km}$ (blue), $19.5 \mathrm{~km}$ (purple), $22.5 \mathrm{~km}$ (maroon) and $25.5 \mathrm{~km}$ (red). Each panel represent one of the four years of overlapping measurements: 2002 in top left, 2003 in top right, 2004 in bottom left and 2005 in bottom right. The mean and standard deviation given in the plots are calculated based on the ratio given in Eq. (8).

extinction coefficient is on average $20 \%$ larger than that from the SAGE III measurements.

\subsection{Zonal average time series}

As a further indication of the level of agreement between OSIRIS and SAGE III we have compared the zonal average time series. Figure 6 shows the daily average $755 \mathrm{~nm}$ extinction ratio profile measured by SAGE III throughout 20022005 in the Northern Hemisphere. The extinction ratio is the ratio of the aerosol extinction coefficient to the molecular extinction at the same wavelength, i.e. the product of the air density and the Rayleigh cross section. The SAGE III measurements are at essentially the same latitude over the course of a day so we have determined the daily average OSIRIS extinction ratio profile for all OSIRIS measurements within $5^{\circ}$ of latitude of the SAGE III measurement. This is also shown in Fig. 6. The average OSIRIS profile is usually composed of between 16 and 32 profiles depending on whether or not the tangent point is illuminated on both the ascending and descending tracks of the Odin orbit. For both instruments, the daily profile is only shown when both instruments are able to make a measurement. The latitude of the SAGE III measurement and the solar zenith angle of the OSIRIS retrievals is also provided for reference. 


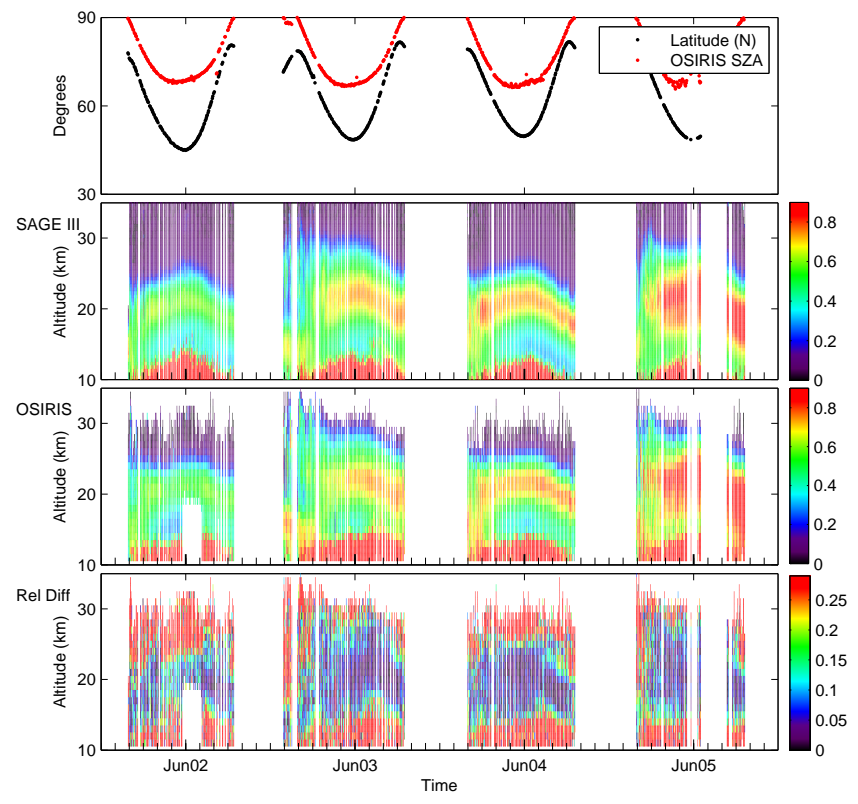

Fig. 6. A time series of the SAGE III, OSIRIS, and absolute relative difference aerosol extinction ratio profiles as a daily zonal average. Data is only shown when both instruments are making measurements; periods when sunlit measurements are not possible for OSIRIS due to solar zenith angle greater than $90^{\circ}$ or when OSIRIS was turned off for engineering tests are indicated in white. OSIRIS profiles include all measurements within $\pm 5^{\circ}$ of the SAGE III average daily latitude. From top to bottom, the plots show the latitude and solar zenith angle of the measurements, the SAGE III zonal average, the OSIRIS zonal average and the absolute relative difference between the two zonal average measurements.

The time series measured by the two instruments are extremely similar; the Junge layer is clearly visible in each year with the peak between approximately 18 and $21 \mathrm{~km}$. The systematic rising and falling essentially driven by the shifting latitude of the measurement toward lower latitudes in the summer. In both cases the aerosol levels are notably high through 2005, likely associated with transport of the aerosol enhancement from the tropical eruption of Mt. Manam $\left(4^{\circ} \mathrm{S}\right.$, $145^{\circ} \mathrm{E}$ ) in January 2005 (Vernier et al., 2011; Vanhellemont et al., 2010). The bottom panel of the figure shows the absolute value of the percent difference between the daily average profile of extinction ratio. Again, the result is similar with percent differences of less than approximately $10 \%$ throughout the bulk of the stratospheric layer and with larger differences above and below. The large values of extinction ratio that occur at low altitude, particularly in the summer as the measurements progress toward lower latitude, are associated with aerosol and cloud near and below the tropopause. Although both instruments measure much larger values at these low altitudes, the microphysical assumptions about the aerosol composition required for the OSIRIS retrievals break down and it is not expected that the OSIRIS results are trust-

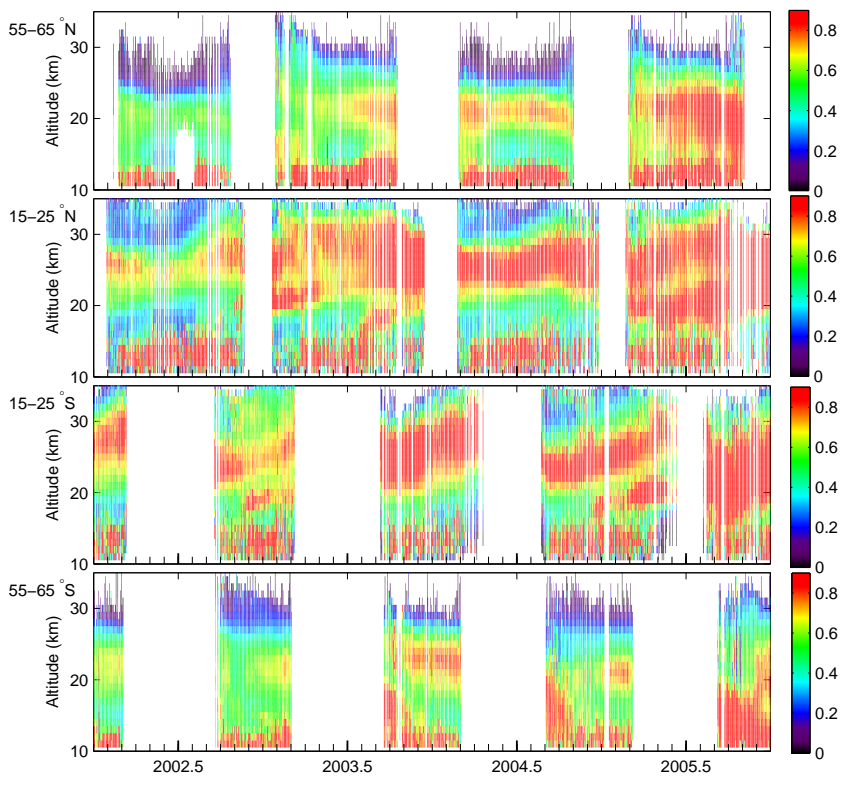

Fig. 7. The daily zonal average OSIRIS aerosol extinction ratio for the SAGE III time period for the following latitude bands shown from top to bottom: $55-65^{\circ} \mathrm{N}, 15-25^{\circ} \mathrm{N}, 15-25^{\circ} \mathrm{S}$, and $55-65^{\circ} \mathrm{S}$. Periods when sunlit measurements are not possible due to solar zenith angle greater than $90^{\circ}$ or when OSIRIS was turned off for engineering tests are indicated in white.

worthy. The assumptions of a typical background (nonvolcanic) aerosol particle size distribution may also explain the bias in the OSIRIS results in 2005 after the eruption of Mt. Manam. The SAGE III mission occurred when aerosol levels were at historically low levels with relatively little volcanic perturbation over the four years. This, and the fact that no measurements were made at tropical latitudes makes this study incomplete in terms of a full validation of the OSIRIS aerosol retrievals; however, it does show that for the conditions that we were able to study, the OSIRIS results are of scientific applicability with an accuracy of about $10 \%$, which is on the same order as the occultation measurements over the same time period.

\section{The OSIRIS Version 5 aerosol extinction data set}

One of the biggest strengths of the OSIRIS aerosol extinction coefficient data product is the relatively good global coverage obtained with the limb scatter technique. To demonstrate this and further show some features of the data set, we have included in Fig. 7 plots of the daily zonal average extinction ratio in four latitude bands throughout the same 20022005 time period shown in Fig. 6. These latitude bands, from the top panel to the bottom panel, are $55-65^{\circ} \mathrm{N}, 15-$ $25^{\circ} \mathrm{N}, 15-25^{\circ} \mathrm{S}$, and $55-65^{\circ} \mathrm{S}$. The highly variable nature of the stratospheric layer, with time and latitude, is clear. Overall, the tropical layer is consistently extended to higher 
altitude. Plumes of rising enhanced extinction from volcanic eruptions are evident in the tropical time series. The effect of Mt. Manam is first seen in the $15-25^{\circ} \mathrm{S}$ time series in January 2005. The enhancement rises slowly and becomes indistinguishable from the bulk layer toward the end of the year. A similar effect is seen in the $15-25^{\circ} \mathrm{N}$ time series. A smaller plume is also observed in 2002-2003 from the eruptions of Ruang $\left(2^{\circ} \mathrm{N}, 125^{\circ} \mathrm{E}\right)$ in September 2002, and Reventador $\left(0^{\circ} \mathrm{S}, 77^{\circ} \mathrm{W}\right)$ in November 2002 (Thomason et al., 2008; Vernier et al., 2011). An additional small plume from an unidentified eruption, which begins at quite high altitude compared to the others, is also observed in the latter half of 2003.

\section{Conclusions}

The OSIRIS Version 5 data product, which is now publicly available for the entire Odin mission (see http://odin-osiris. usask.ca/) includes retrievals of vertical profiles of the stratospheric aerosol extinction coefficient at $750 \mathrm{~nm}$. The retrieval algorithm is based on the work of Bourassa et al. (2007) and is further improved as detailed here. These improvements include the modified retrieval vector formulation with better sensitivity and a normalization technique that incorporates multiple high altitude radiance measurements to minimize the impact of measurement noise. Additionally, a coupled retrieval of the effective scene albedo and the aerosol extinction profile has been found to improve the results at the $10 \%$ level.

Comparisons of coincident measurements made by SAGE III at $755 \mathrm{~nm}$ between 2002 and 2005 show excellent agreement to within approximately $10 \%$ over the bulk of the stratospheric layer from about 15 to $25 \mathrm{~km}$. This is essentially at the level of precision and accuracy expected from the SAGE III data, as reported by Thomason et al. (2010). We do not recommend the use of this data product at altitudes below the tropopause, where cloud scattering will tend to bias the retrieved result due to the same issue of incorrect forward modelling with the assumed particle size, shape and composition of background stratospheric sulphate aerosol. In 2005 the OSIRIS retrievals of aerosol extinction coefficient are systematically up to $20 \%$ larger than SAGE III retrievals, which may be explained in some part by a systematic error arising from volcanic aerosol from the eruption of Mt. Manam affecting the particle size distribution. The SAGE III intercomparison does not provide any indication of the fidelity of the OSIRIS retrievals in the tropics, or for the time period after 2005, where in both cases any systematic error that arises from the influence of volcanic eruptions is likely to be more significant; however, it does show that the limb scatter retrievals are of good quality with scientific applicability throughout the bulk of the stratospheric aerosol layer for the conditions of low volcanic load encountered during 2002-2005.
Acknowledgements. This work was supported by the Natural Sciences and Engineering Research Council (Canada) and the Canadian Space Agency. Odin is a Swedish-led satellite project funded jointly by Sweden (SNSB), Canada (CSA), France (CNES) and Finland (Tekes). The SAGE III data were obtained from the NASA Langley Research Center EOSDIS Distributed Active Archive Center.

Edited by: W. Lahoz

\section{References}

Bertaux, J. L., Kyrölä, E., Fussen, D., Hauchecorne, A., Dalaudier, F., Sofieva, V., Tamminen, J., Vanhellemont, F., Fanton d'Andon, O., Barrot, G., Mangin, A., Blanot, L., Lebrun, J. C., Pérot, K., Fehr, T., Saavedra, L., Leppelmeier, G. W., and Fraisse, R.: Global ozone monitoring by occultation of stars: an overview of GOMOS measurements on ENVISAT, Atmos. Chem. Phys., 10, 12091-12148, doi:10.5194/acp-10-12091-2010, 2010.

Bourassa, A. E., Degenstein, D. A., Gattinger, R. L., and Llewellyn, E. J.: Stratospheric aerosol retrieval with OSIRIS limb scatter measurements, J. Geophys. Res., 112, D10217, doi:10.1029/2006JD008079, 2007.

Bourassa, A. E., Degenstein, D. A., and Llewellyn, E. J.: SASKTRAN: A spherical geometry radiative transfer code for efficient estimation of limb scattered sunlight, J. Quant. Spectrosc. Ra., 109, 52-73, 2008a.

Bourassa, A. E., Degenstein, D. A., and Llewellyn, E. J.: Retrieval of stratospheric aerosol size information from OSIRIS limb scattered sunlight spectra, Atmos. Chem. Phys., 8, 63756380, doi:10.5194/acp-8-6375-2008, 2008b.

Bourassa, A. E., McLinden, C. A., Sioris, C. E., Brohede, S., Bathgate, A. F., Llewellyn, E. J., and Degenstein, D. A.: Fast $\mathrm{NO}_{2}$ retrievals from Odin-OSIRIS limb scatter measurements, Atmos. Meas. Tech., 4, 965-972, doi:10.5194/amt-4-965-2011, 2011.

Bovensmann, H., Burrows, J. P., Buchwitz, M., Frerick, J., Noël, S., Rozanov, V. V., Chance, K. V., and Goede, A. P. H.: SCIAMACHY: Mission Objectives and Measurement Modes, J. Atmos. Sci., 56, 127-150, 1999.

Degenstein, D. A., Llewellyn, E. J., and Lloyd, N. D.: Tomographic retrieval of the oxygen infrared atmospheric band with the OSIRIS infrared imager, Can. J. Phys., 82, 501-515, 2004.

Degenstein, D. A., Bourassa, A. E., Roth, C. Z., and Llewellyn, E. J.: Limb scatter ozone retrieval from 10 to $60 \mathrm{~km}$ using a multiplicative algebraic reconstruction technique, Atmos. Chem. Phys., 9, 6521-6529, doi:10.5194/acp-9-6521-2009, 2009.

Deshler, T., Hervig, M. E., Hofmann, D. J., Rosen, J. M., and Liley, J. B.: Thirty years of in-situ stratospheric aerosol size distribution measurements from Laramie, Wyoming (41 N), using balloon-borne instruments, J. Geophys. Res., 108, 1-13, doi:10.1029/2002JD002514, 2003.

Llewellyn, E. J., Lloyd, N. D., Degenstein, D. A., Gattinger, R. L., Petelina, S. V., Bourassa, A. E., Wiensz, J. T., Ivanov, E. V., McDade, I. C., Solheim, B. H., McConnell, J. C., Haley, C. S., von Savigny, C., Sioris, C. E., McLinden, C. A., Griffioen, E., Kaminski, J., Evans, W. F., Puckrin, E., Strong, K., Wehrle, V., Hum, R. H., Kendall, D. J. W., Matsushita, J., Murtagh, D. P., Brohede, S., Stegman, J., Witt, G., Barnes, G., Payne, W. F., Piché, L., Smith, K., Warshaw, G., Deslauniers, D.-L., Marc- 
hand, P., Richardson, E. H., King, R. A., Wevers, I., McCreath, W., Kyrölä, E., Oikarinen, L., Leppelmeier, G. W., Auvinen, H., Mégie, G., Hauchecorne, A., Lefèvre, F., de La Nöe, J., Ricaud, P., Frisk, U., Sjoberg, F., von Schéele, F., and Nordh, L.: The OSIRIS instrument on the Odin spacecraft, Can. J. Phys., 82, 411-422, 2004.

Murtagh, D., Frisk, U., Merino, F., Ridal, M., Jonsson, A., Stegman, J., Witt, G., Eriksson, P., Jiménez, C., Megie, G., de La Noë, J., Ricaud, P., Baron, P., Pardo, J. R., Hauchecorne, A., Llewellyn, E. J., Degenstein, D. A., Gattinger, R. L., Lloyd, N. D., Evans, W. F. J., McDade, I. C., Haley, C. S., Sioris, C., von Savigny, C., Solheim, B. H., McConnell, J. C., Strong, K., Richardson, E. H., Leppelmeier, G. W., Kyrölä, E., Auvinen, H., and Oikarinen, L.: Review: An overview of the Odin atmospheric mission, Can. J. Phys., 80, 309-319, 2002.

Randall, C. E., Bevilacqua, R. M., Lumpe, J. D., and Hoppel, K. W.: Validation of POAM III aerosols: Comparison to SAGE II and HALOE, J. Geophys. Res., 106, 27525-27536, doi:10.1029/2001JD000528, 2001.

Rault, D. F.: Ozone profile retrieval from Stratospheric Aerosol and Gas Experiment (SAGE III) limb scatter measurements, J. Geophys. Res., 110, D09309, doi:10.1029/2004JD004970, 2005.

Rault, D. and Loughman, R.: Stratospheric and upper tropospheric aerosol retrieval from limb scatter signals, Proc. SPIE, 6745, 674509, doi:10.1117/12.737325, 2007.

Thomason, L. W., Burton, S. P., Luo, B.-P., and Peter, T.: SAGE II measurements of stratospheric aerosol properties at non-volcanic levels, Atmos. Chem. Phys., 8, 983-995, doi:10.5194/acp-8-9832008, 2008.
Thomason, L. W., Moore, J. R., Pitts, M. C., Zawodny, J. M., and Chiou, E. W.: An evaluation of the SAGE III version 4 aerosol extinction coefficient and water vapor data products, Atmos. Chem. Phys., 10, 2159-2173, doi:10.5194/acp-10-21592010, 2010.

Tukiainen, S., Hassinen, S., Seppala, A., Auvinen, H., Kyrola, E., Tamminen, J., Haley, C., Lloyd, N., and Verronen, P.: Description and validation of a limb scatter retrieval method for Odin/OSIRIS, J. Geophys. Res., 113, D04308, doi:10.1029/2007JD008591, 2008.

Vanhellemont, F., Fussen, D., Mateshvili, N., Tétard, C., Bingen, C., Dekemper, E., Loodts, N., Kyrölä, E., Sofieva, V., Tamminen, J., Hauchecorne, A., Bertaux, J.-L., Dalaudier, F., Blanot, L., Fanton d'Andon, O., Barrot, G., Guirlet, M., Fehr, T., and Saavedra, L.: Optical extinction by upper tropospheric/stratospheric aerosols and clouds: GOMOS observations for the period 2002 2008, Atmos. Chem. Phys., 10, 7997-8009, doi:10.5194/acp-107997-2010, 2010.

Vernier, J., Thomason, L., Pommereau, J.-P., Bourassa, A., Pelon, J., Garnier, A., Hauchecorne, A., Blanot, L., Trepte, C., Degenstein, D., and Vargas, F.: Major influence of tropical volcanic eruptions on the stratospheric aerosol layer during the last decade, Geophys. Res. Lett., 38, L12807, doi:10.1029/2011GL047563, 2011. 